\title{
O CAMINHAR ACADÊMICO E PROFISSIONAL DE DUAS PROFESSORAS EM EDUCAÇÃO ESTATÍSTICA
}

- THAYS RODRIGUES VOTTO

Universidade Federal do Rio Grande

- KARLA PRISCILA SCHREIBER

Universidade Federal do Rio Grande

MAUREN PORCIÚNCULA

Universidade Federal do Rio Grande

Este artigo apresenta a trajetória e as experiências de duas professoras, primeiras autoras do mesmo, que se encontraram no doutorado, sob orientação da terceira, narrando a partir do espaço tridimensional da pesquisa, o encontro das docentes com as temáticas estudadas na pós-graduação, bem como sobre os fazeres, idas e vindas que as levaram ao campo da educação. A partir da autobiografia das docentes, espera-se analisar as experiências que as constituíram como sujeitos, professoras e pesquisadoras no campo da Educação Estatística. As narrativas apresentam tanto os sentimentos, memórias e experiências das docentes que as levaram ao campo da educação, desde a infância, quanto aos lugares e pessoas que marcaram essas experiências. Em suma, percebeu-se que o sujeito professor se constitui não somente a partir da conclusão de um curso de graduação, mas, sim, ao longo de toda a sua história de vida, das suas experiências com os outros desde a infância, com seus professores e colegas, na interação com seus pares, envolvendo aspectos afetivos que vão direcionando os sujeitos para esta ou aquela área, que, nesse caso, culminou na pesquisa científica no campo da Educação Estatística.

Palavras-chave: Narrativa. Trajetória docente. Experiências docentes. Educação Estatística.

\section{ABSTRACT THE ACADEMIC AND PROFESSIONAL WALK OF TWO TEACHERS IN STATISTICAL EDUCATION}

This paper presents the trajectory and experiences of two teachers, first authors, who met in the doctorate under the guidance of the third, narrating from the three-dimensional space of the research, 
the meeting of the teachers with the subjects studied in the postgraduate, as well as, the doings, comings and goings that the led to the field of education. From the autobiography of the teachers it is hoped to analyze the experiences that constituted them as subjects, teachers and researchers in the field of Statistical Education. The narratives present both the feelings, memories and experiences of teachers that have taken them to the field of education since childhood, as well as the places and people that marked these experiences. In short, it was perceived that the teacher subject is constituted not only from the conclusion of an undergraduate course, but, throughout his life history, from his experiences with others from childhood, with his teachers and colleagues in the interaction with their peers, involving affective aspects that will direct the subjects to this or that area, which in this case culminated in the scientific research in the field of Statistical Education.

Keywords: Narrative. Teaching trajectory. Teaching experiences. Statistical education.

\section{RESUMEN EL CAMINAR ACADÉMICO Y PROFESIONAL DE DOS PROFESORAS EN EDUCACIÓN ESTADÍSTICA}

Este artículo presenta la trayectoria y las experiencias de dos profesoras, primeras autoras del mismo, que se encontraron en el doctorado bajo la orientación de la tercera, que narran desde el espacio tridimensional de la investigación, el encuentro de las docentes con las temáticas estudiadas en el posgrado, bien como, sobre los haceres, idas y venidas que las llevaron al campo de la educación. Desde la autobiografia de las docentes se espera analizar las experiencias que las constituyeron como sujetos, profesoras e investigadoras en el campo de la Educación Estadística. Las narrativas presentan tanto los sentimientos, memorias y experiencias de las docentes que las llevaron al campo de la educación desde la niñez, como los lugares y personas que marcaron esas experiencias. En resumen, se percibió que el sujeto profesor se constituye no solamente desde la conclusión de un curso de graduación, pero sí, a lo largo de toda su historia de vida, de sus experiencias con los otros desde la niñez, con sus profesores y colegas, en la interacción con sus pares, involucrando aspectos afectivos que van direccionando los sujetos para esta o aquella área, que, en este caso, culminó en la investigación científica en el campo de la Educación Estadística.

Palabras clave: Narrativa. Trayectoria docente. Experiencias docentes. Educación estadística. 


\section{Introdução}

Pensar e escrever narrativamente implica experienciar, relembrar uma experiência e contá -la, considerando alguns termos que compõem o espaço tridimensional de pesquisa narrativa, sendo: pessoal e social (interação); passado, presente e futuro (continuidade); lugar (situação). Com isso, "os estudos têm dimensões e abordam assuntos temporais; focam no pessoal e no social em um balanço adequado para a investigação; e ocorrem em lugares específicos ou sequências de lugares" (CLANDININ; CONNELLY, 2015, p. 85).

Considerando o espaço tridimensional da pesquisa narrativa, este artigo apresenta a trajetória e as experiências de duas professoras, uma Pedagoga e uma Licenciada em Matemática, autoras deste artigo, sob orientação da terceira, indicando o encontro destas docentes com as temáticas estudadas na pósgraduação, 'bem como sobre os fazeres, idas e vindas que as levaram ao campo da educação. Para isso, são narradas as experiências que as constituíram como sujeitos, professoras e pesquisadoras no campo da Educação Estatística.

A intersecção do caminhar destas professoras encontra-se no interesse e na preocupação em investigar os processos de ensinar e aprender Estatística. Com isso, as pesquisas estão relacionadas a estudantes da Educação Básica - dos Anos Iniciais e do Ensino Fundamental e a processos formativos com professores em contextos colaborativos.

A Educação Estatística, área de interesse destas pesquisadoras, tem como propósito "estudar e compreender como as pessoas ensinam e aprendem Estatística, o que envolve os aspectos cognitivos e afetivos do ensino-aprendizagem, além da epistemologia dos

1 As duas professoras, primeiras autoras deste artigo, são doutorandas do Programa de Pós-Graduação em Educação em Ciências: Química da Vida e Saúde pela Universidade Federal do Rio Grande - FURG, orientadas pela terceira autora. conceitos estatísticos e o desenvolvimento de métodos e materiais de ensino" (CAZORLA; KATAOKA; SILVA, 2010, p. 22-23). Neste caso, “A Educação Estatística não apenas auxilia a leitura e a interpretação de dados, mas fornece a habilidade para que uma pessoa possa analisar e relacionar criticamente os dados apresentados, questionando e até mesmo ponderando sua veracidade" (LOPES, 2010, p. 52). Logo, diferencia-se da Estatística, como método estatístico, a qual se configura como base para o desenvolvimento de métodos científicos (BATANERO, 2001).

A partir deste entendimento ressalta-se que a Estatística está preconizada nos documentos oficiais que regem a Educação Básica brasileira. Primeiramente, nos Parâmetros Curriculares Nacionais - PCN (BRASIL, 1997; 1998; 2000; 2006) e, mais recentemente, na Base Nacional Comum Curricular - BNCC (BRASIL, 2018).

Nos PCN, a Estatística foi inserida na área da Matemática, especificamente em 1997, orientando o ensino nos Anos Iniciais do Ensino Fundamental. Nesse documento, também foram pautados alguns princípios e, dentre eles, um, em especial, recomenda que as práticas de Matemática, no cotidiano escolar, não podem instigar nos alunos um olhar para os objetos prontos e definitivos. Com isso, espera-se que a prática pedagógica do professor, desse nivel de ensino, possibilite a construção e a apropriação de um conhecimento pelo aluno, que se servirá dele para compreender e transformar a própria realidade (BRASIL, 1997).

Para os Anos Finais do Ensino Fundamental, a Estatística encontra-se, juntamente com a Probabilidade e a Combinatória, no bloco denominado "Tratamento da Informação". Neste caso, em relação à Estatística, espera-se que o estudante possa "construir procedimentos para coletar, organizar, comunicar dados, utilizando tabelas, gráficos e representações que 
aparecem frequentemente em seu dia a dia", assim como, o cálculo de "medidas estatísticas como média, mediana e moda com o objetivo de fornecer novos elementos para interpretar dados estatísticos" (BRASIL, 1998, p. 52), habilidades estas que devem ser aprimoradas no Ensino Médio (BRASIL, 2000; 2006).

Mais recentemente, a BNCC apresentou, como objetivos para o ensino de Matemática na Educação Básica, o estabelecimento de conexões entre os eixos da Matemática e outras áreas do saber; a resolução de problemas, a criação de estratégias próprias para a sua resolução, desenvolvendo a sua imaginação e criatividade; raciocínio, o desenvolvimento de abstrações baseadas em situações concretas, generalização, a organização e a representação; comunicação, utilizando as diversas formas de linguagem empregadas em Matemática; e o uso da argumentação matemática apoiada em vários tipos de raciocínios. Estes foram organizados em cinco eixos, sendo: Geometria; Grandezas e Medidas; Estatística e Probabilidade; Números e Operações; Álgebra e Funções (BRASIL, 2018).

Concernente aos Anos Iniciais, a BNCC enfatiza o desenvolvimento de habilidades de pesquisa desde o primeiro ano da alfabetização, ainda que de maneira informal e, conforme o aluno avança na sua trajetória escolar, devem ser ampliadas e intensificadas, gradativamente, as habilidades referentes à pesquisa científica escolar. Além disso, inclui a construção e interpretação de gráficos e tabelas oriundos de pesquisa tanto no universo da turma, quanto da escola e comunidade, valendo-se de temas transversais e de outras áreas do conhecimento (BRASIL, 2018).

Para os Anos Finais do Ensino Fundamental espera-se que "os alunos saibam planejar e construir relatórios de pesquisas estatísticas descritivas, incluindo medidas de tendência central e construção de tabelas e diversos ti- pos de gráfico". Tal fato requer um planejamento em que possam ser consideradas "questões relevantes e da população a ser pesquisada, a decisão sobre a necessidade ou não de usar amostra e, quando for o caso, a seleção de seus elementos por meio de uma adequada técnica de amostragem" (BRASIL, 2018, p. 275), sendo no Ensino Médio dada a continuidade, buscando, ainda, "a construção de uma visão integrada da Matemática, aplicada à realidade, em diferentes contextos" (BRASIL, 2018, p. 528).

A partir deste contexto, para contemplar o objetivo proposto, nas próximas seções são apresentadas as narrativas de duas professoras (primeiras autoras do artigo), escritas em primeira pessoa, as quais dissertam sobre as experiências, memórias e emoções inerentes à constituição do sujeito como pessoa, como professor, outrossim como pesquisador da Educação Estatística. Na sequência, são indicadas algumas considerações.

\section{Da infância à vida adulta: trajetória acadêmica e profissional da professora Thays}

O presente texto narra a trajetória acadêmica e profissional de Thays, os fazeres, idas e vindas, sentimentos e emoções que a levaram até à docência.

Comecemos então pela minha escolha profissional. Lembro-me que, na infância, quando era questionada: "o que queres ser quando crescer?" - eu respondia: "professora e veterinária". Na época, com seis ou sete anos, eu amava o espaço da escola, as interações desse lugar, o cheiro, as cores, os sentimentos que estar e pertencer àquela escola me proporcionavam. Nessa direção, saliento que as palavras determinam nosso pensamento porque não pensamos com pensamentos, mas com palavras, portanto, outrossim, tem a ver com as palavras "o modo como nos colocamos diante 
de nós mesmos, diante dos outros e diante do mundo em que vivemos. E o modo como agimos em relação a tudo isso" (LARROSA, 2002, p. 21). Naquela época, talvez eu não compreendesse todos os sentidos que a palavra professora poderia ter e a grande responsabilidade que tal profissão trazia em seu bojo, mas eu segui convicta do que gostaria de ser.

Conforme ia crescendo, pouco a pouco, em torno de 10 ou 11 anos, a minha resposta a essa indagação permanecia quase a mesma, tirando a profissão de veterinária, que declinei quando soube que eu precisaria operar os animais e vê-los, por vezes, morrer. Então, mantive minha escolha, por ser professora, e continuava gostando de animais. Certa vez, uma prima disse-me o seguinte sobre minha escolha profissional: "toda criança quer ser professora por causa do amor pela sua primeira professora, você só está carregando isso por mais tempo". Na época, com 10 anos, eu não soube compreender o sentido daquela frase. Lembro-me de ficar brava com aquele comentário, e responder que eu gostava do ambiente da escola e da ideia de ajudar os outros a estudarem e aprenderem, e que por isso eu queria ser professora. Esse era o sentido que eu atribuía, naquele momento, a essa escolha profissional. Nessa direção, Larrosa salienta que:

quando fazemos coisas com as palavras, do que se trata é de como damos sentido ao que somos e ao que nos acontece, de como correlacionamos as palavras e as coisas, de como nomeamos o que vemos ou o que sentimos e de como vemos ou sentimos o que nomeamos. (LARROSA, 2002, p. 21)

A forma como sentimos e experenciamos as coisas tendem a se modificar, conforme contamos e recontamos algum fato ou acontecimento, como o relatado acima. Neste fato, reside a beleza da narrativa, que nos proporciona uma escrita e os sentidos dialéticos a ela imbricados. O texto narrativo opera como um instrumento mental de construção de realidade, e, dentre outros fatores, Bruner (1991, p. 6-7) infere que: "narrativas são sobre pessoas que agem em um cenário, e os acontecimentos devem ser pertinentes a seus estados intencionais enquanto estiverem atuando - com suas convicções, desejos, teorias, valores, e assim por diante".

Hoje, penso e sinto aquela situação de forma diferente. Acredito que, em parte, minha prima poderia estar certa, tendo em vista que uma parcela do que me fez optar pela docência advém, sim, do tempo em que eu era criança e de como eu me sentia feliz no espaço escolar, a ponto de chorar quando a escola fazia feriadão, ou paralisações, nos quais eu não poderia ir para a escola. Então, sim, parte da minha escolha profissional origina-se nesse ideal de infância, na romantização da criança pela sua primeira professora. Com o passar dos anos, esse romance foi amadurecendo, culminando na minha jornada profissional, a começar pelo Magistério, graduação em Pedagogia, graduação em Psicologia, mestrado em Educação em Ciências e, atualmente, doutorado em Educação em Ciências, e tantos temas que eu gostaria ainda de estudar, para que eu possa me tornar, a cada dia, uma profissional da educação com mais subsídios para alicerçar a minha prática pedagógica.

À medida que explicamos nossas próprias ações e os eventos humanos que acontecem à nossa volta, principalmente em termos de narrativa, história, drama, é concebível que nossa sensibilidade à narrativa constitua a principal ligação entre nosso próprio sentido de self e nosso sentido de outros, no mundo social à nossa volta (BRUNER, 1997). A narrativa nos permite esse ir e vir, essa flutuação pelos espaços temporais e que implicam diferentes sensações, reações e sentimentos. Lembro-me que, na ocasião em que minha prima me fez esse apontamento, eu fiquei extremamente fu- 
riosa. Tal sentimento, hoje, tornou-se gratidão. A partir da dimensão introspectiva, dissertada por Clandinin e Connelly (2015), uma vez que compreendo, como disse anteriormente, que foi, sim, o amor pela minha professora, atrelado ao gosto pelo ambiente escolar e tudo que dele se originava que me fez querer a carreira docente e persistir nesse ideal, buscando a minha profissionalização na área.

Esse espaço foi tão marcante para mim, que a minha primeira memória de infância diz respeito a uma situação de brincadeira, no jardim de infância, como era chamado naquela época, a Educação Infantil, quando eu tinha cinco anos. Tal memória versa sobre a brincadeira com uma boneca de papel, que tinha diversas roupinhas, também de papel, que eu dobrava e colocava nela, sendo um brinquedo muito requisitado. Lembro-me da sensação de bem-estar, plenitude e alegria, quando eu conseguia brincar com esse brinquedo. Larrosa (2002, p. 21) disserta sobre a experiência, caracterizando-a como sendo "o que nos passa, o que nos acontece, o que nos toca. Não o que se passa, não o que acontece, ou o que toca", uma vez que todos os dias se passam muitas coisas, entretanto, ao mesmo tempo, quase nada nos acontece. A experiência com esse brinquedo me tocou, por vários motivos, alguns ainda inconscientes, mas penso que pelo sentimento que tal experiência me proporcionou, eu a tenha guardado na memória.

A partir dessa lembrança, disserto sobre o meu tema de pesquisa do mestrado e que trago também para o doutorado: a ludicidade. Luckesi (1998) atribui ao lúdico uma dimensão subjetiva, ou seja, não o simples manuseio de brinquedos ou participação em jogos e brincadeiras. $O$ autor infere que a ludicidade é um fenômeno interno do sujeito que vivencia uma situação, que the permita a plenitude da experiência, trazendo bem-estar, alegria e, também, por vezes, prazer. Seja ela de diferentes ordens, desde a leitura de um livro, dançar, estar na presença de amigos queridos etc.

Diante desse conceito, percebo que minha primeira lembrança de infância e de vida se configura como um momento lúdico, uma vez que me proporcionou sentimentos lúdicos. Então, ainda hoje, aquela experiência me toca, me instiga e me motiva. Aqueles sentimentos de plenitude e alegria me fazem pensar e repensar o lugar da escola, do professor e do conhecimento, e como esses lugares juntos podem operar de forma lúdica na vida e formação do sujeito/aluno.

É no espaço tridimensional, envolvendo o fator pessoal e social da interação, os sentimentos oriundos das experiências narradas acima, vivenciadas no passado, que ainda se modificam e se transformam no presente, que me permitem enxergar uma possibilidade de futuro, estabelecendo uma continuidade dessa experiência, a partir do lugar da escola e das situações e lembranças que me constituem esse lugar.

Durante o mestrado, eu pesquisei a ludicidade presente ou emergente nas estratégias para o ensino e a aprendizagem estatística (VOTTO, 2018). Nesse ponto, acho pertinente fazer uma volta ao passado, novamente, sobre o meu encontro com a área da Estatística e da ludicidade. Durante a minha segunda graduação, em Psicologia, cursei disciplinas de Estatística com a professora que viria a ser minha orientadora, mas, antes disso, entrei no Programa de Educação Tutorial - PET Conexões e Saberes Estatísticos da Universidade Federal do Rio Grande - FURG, por ela coordenado. Ressalto que:

o significado da palavra Estatística, enquanto ciência refere-se ao conjunto de ferramentas para obter, resumir e extrair informações relevantes de dados; encontrar e avaliar padrões mostrados pelos mesmos; planejar levantamentos de dados ou delinear experimentos e comunicar resultados de pesquisas quantitati- 
vas. Sua importância reside no auxílio ao processo de pesquisa, que permeia todas as áreas do conhecimento que lidam com observações empíricas. Assim, podemos dizer que a Estatística é a ciência do significado e uso dos dados. (CAZORLA et al., 2017, p. 14)

Foi durante a experiência de viver intensamente o ensino, a pesquisa e a extensão, proporcionado pela participação no PET, que me fez adentrar o meio científico. Principalmente, a participação em um projeto de extensão chamado LEME - Letramento Multimidia Estatístico, que consiste em oferecer oficinas de Letramento Estatístico, destinado a jovens em situação de vulnerabilidade social, que realizam cursos profissionalizantes, nas mais diversas áreas, tais como manicure, panificação, auxiliar administrativo, informática, entre outros.

O intuito do projeto era, e ainda é, desenvolver um trabalho estatístico com os alunos, possibilitando-lhes a construção das habilidades necessárias para ler e interpretar as informações, compreendendo como são produzidas as informações para, portanto, serem desenvolvidas suas autonomias e criticidades. Pautando suas ações e fazeres nos pressupostos de Gal (2002), de que a construção de conhecimentos acerca dessa ciência, nas escolas, torna-se necessária, tendo em vista o grande número de informações às quais somos submetidos diariamente, por meio das mídias digitais e/ou impressas. Tal demanda faz com que os cidadãos precisem desenvolver habilidades e competências específicas para compreender, de forma reflexiva, tais informações, nos âmbitos escolar, profissional ou pessoal (GAL, 2002; 2015).

Outrossim, foi durante as reuniões de planejamento para atuação nesse projeto de extensão, que eu comecei a estudar a ludicidade, pensando em formas de deixar as oficinas mais dinâmicas e alegres, enquanto proporcionava aos estudantes a construção do conhecimen- to estatístico. Nessa época, acreditava que a ludicidade estava fortemente relacionada aos jogos e brincadeiras, e, pensando nisso, adaptamos alguns jogos e os inserimos nas oficinas, tendo uma boa receptividade dos alunos. Busquei conhecimentos acerca dos jogos e da ludicidade, primeiramente com Kishimoto. A autora elucida que o brincar dá à criança um poder, o de "tomar decisões, expressar sentimentos e valores, conhecer a si, aos outros e o mundo, de repetir ações prazerosas, de partilhar, expressar sua individualidade e identidade por meio de diferentes linguagens" (KISHIMOTO, 2010, p. 1). No que tange aos jogos, Kishimoto (1998) apresenta duas funções do jogo educativo, a saber: a função lúdica, compreendida como aquela que propicia prazer, diversão, alegria e até mesmo desprazer, caracterizada como voluntária e, por outro lado, a função educativa, que consiste em um jogo que ensina um determinado conteúdo, que complete o indivíduo em seu saber.

Diante do exposto até aqui, eu começava a minha produção científica alicerçada nos estudos sobre a ludicidade e a sua contribuição para o campo da Educação Estatística. Assim comecei as primeiras escritas para eventos e a me constituir como uma pesquisadora.

Nessa direção, a minha pesquisa de mestrado englobou a minha curiosidade por compreender quais habilidades estatísticas os professores davam ênfase, em sua prática pedagógica, e se a construção desse conhecimento e a participação em atividades estatísticas poderiam proporcionar aos estudantes sentimentos lúdicos. Quando adentro meus estudos, na área da ludicidade, percebo, apoiada em Luckesi (2005), como mencionado anteriormente, que essa área não compreende puramente ações e objetos, como o brincar e o manuseio de jogos, por exemplo. Mas é um fenômeno interno, subjetivo do sujeito, e, portanto, singular, no qual cada experiência, como 
diz Larrosa (2002), pode tocar o sujeito ou não. Assim, cada ação, atividade, situação pode, ou não, proporcionar ao sujeito a plenitude da experiência, ou seja, o lúdico, de acordo como ele a vivencia, de como ele a sente.

Todos esses entendimentos e compreensões foram aprofundando-se, à medida que eu ia estudando, perpassando a minha construção docente. Alguns desses entendimentos também foram observados nos sujeitos da minha pesquisa de mestrado, onde foi realizada uma pesquisa quantitativa-qualitativa. Da primeira fase, participaram 92 professores da rede municipal de Rio Grande, que responderam a um questionário sobre quais habilidades de Estatística estavam desenvolvendo em sua prática pedagógica. A partir desses resultados, foram selecionados sete professores, que participaram de uma entrevista, configurando a parte qualitativa do estudo (VOTTO, 2018).

Emergiu do corpus analisado, a partir da fase quantitativa, que cerca de $90 \%$ dos professores investigados alegavam desenvolver, em sua prática pedagógica, pelo menos uma habilidade estatística preconizada nos documentos oficiais, seja nos PCN (BRASIL, 1997) ou na BNCC (BRASIL, 2018), embora alguns o fizessem de forma inconsciente. Já a análise qualitativa nos permitiu categorizar os discursos docentes, sob duas categorias gerais. Na primeira delas, o ensino e aprendizagem da Educação Estatística nos Anos Iniciais, constatei que os professores realizavam atividades que envolviam a coleta e a discussão de informações, valendo-se, por vezes, da construção de gráficos e tabelas, e da interpretação destes. Entretanto, uma minoria formalizava todas as etapas do ciclo investigativo de uma pesquisa (VOTTO, 2018).

Com uma menor ênfase atribuída pelos professores à pesquisa escolar científica, se tem uma lacuna na formação dos estudantes, uma vez que a pesquisa no âmbito escolar é uma prática relevante, tendo em vista que está preconizada nos documentos oficiais brasileiros (BRASIL, 1997; 2013; 2018). Além disso, os avanços tecnológicos e a produção acelerada de conhecimentos, característica deste século, requerem um novo comportamento dos professores, que devem deixar de ser transmissores de conhecimentos para serem mediadores, facilitadores da aquisição de conhecimentos (DEMO, 1997; BRASIL 2013). Estes precisam estimular a realização de pesquisas, a produção de conhecimentos e o trabalho em grupo. Essa transformação torna-se necessária e pode ser traduzida pela adoção da pesquisa como princípio pedagógico (BRASIL, 2013).

No que se refere à segunda categoria, Educação Estatística e sua relação com as vivências lúdicas, de modo geral, os docentes compreendiam a ludicidade por meio de sua materialidade em jogos e atividades lúdicas, implicando numa visão stricto sensu do lúdico - assim como eu, durante a participação no projeto de extensão. Em contrapartida, uma minoria compreendia esse fenômeno como uma dimensão subjetiva, conforme enfatiza Luckesi (2005). Em relação às atividades estatísticas, os discursos docentes sugeriam que propostas que envolviam a construção de gráficos, com dados oriundos de pesquisas, com temas do interesse da turma, apresentavam grande potencial lúdico. A esse respeito, Demo (2015) enfatiza que o trabalho com a pesquisa escolar, partindo de motivações lúdicas, pode fazer com que o aluno supere o papel de objeto de massa de manobra, para o de sujeito, concebido como parceiro de trabalho e ativo na construção do seu conhecimento. Dito isso, concebo que a constituição do saber lúdico se apresenta como um dos saberes fundamentais à docência, fazendo-se necessário na formação inicial e continuada dos educadores (SILVA, 2014; VOTTO, 2018).

A partir dos resultados apresentados aci- 
ma, oriundos da minha pesquisa de mestrado, eu escolho estudar no doutorado, em andamento, a pesquisa escolar científica, uma vez que ela se apresentou como uma lacuna no processo de ensino-aprendizagem, nos Anos Iniciais do Ensino Fundamental. Esta está ocorrendo por meio de uma pesquisa-investigação, no âmbito da formação de professores, para uma educação potencialmente lúdica.

Por fim, destaco que o modo narrativo que utilizei para contar as minhas experiências e escolhas profissionais, pautadas em sentimentos e vivências, tanto infantis como adultas, leva a conclusões não sobre certezas num mundo primitivo, mas sobre as diversas perspectivas que podem ser construídas para tornar a experiência compreensível. A narrativa trata das vicissitudes das intenções humanas, organizando a sua experiência de uma forma tão profunda como em uma obra de arte (BRUNER, 1991; 1997).

\section{Da Licenciatura em Matemática} à pesquisa em Educação

\section{Estatística: trajetória acadêmica e profissional da professora Karla}

Este texto narra a trajetória acadêmica e profissional de Karla, trazendo as experiências que contribuíram para a sua constituição, como professora de Matemática e pesquisadora na área de Educação Estatística, mais especificamente, na formação de professores em contextos colaborativos. As histórias de formação, vividas no fazer profissional, são expostas e analisadas no espaço tridimensional da pesquisa narrativa.

O espaço tridimensional está entrelaçado a dois contextos distintos: o exercício da docência na disciplina de Matemática e um curso de pós-graduação - em nível de doutorado. 0 primeiro espaço é constituído a partir de duas experiências como professora de Matemática, não concomitantes - o ensino de Matemática para estudantes do 60 ano do Ensino Fundamental, em uma instituição de ensino particular, e, posteriormente, com discentes do Ensino Médio, em uma instituição pública federal.

No segundo contexto, o curso de pós-graduação, a ênfase está nas discussões acerca das contribuições de um contexto colaborativo na mobilização de práticas pedagógicas e na sistematização de saberes profissionais, na perspectiva do Letramento Estatístico, por professores que atuam na Educação Básica e no Ensino Superior. A pesquisa, assim como a docência e a participação no grupo colaborativo, são espaços que se entrelaçam, em um processo de aprender e partilhar histórias, baseadas nas experiências pessoais e construídas com a presença do outro, sendo aqui narradas.

A reflexão e a reconstrução das experiências são importantes na formação docente, apesar de não ser um processo fácil, pois não esteve tão presente no decorrer do meu desenvolvimento profissional e acadêmico. Tal fato é coerente ao já ressaltado por Freitas e Fiorentini (2008, p. 139), os quais afirmam que "os futuros professores de Matemática apresentam dificuldade em colocar no papel suas reflexões e seus pensamentos, o que leva a supor que os cursos de graduação em Matemática pouco enfatizam e exploram as interações mediadas pela escrita discursiva".

A ausência destas reflexões pode ocorrer devido à ênfase atribuída à escrita técnica, ocasionando uma perda em relação à escrita reflexiva, discursiva e narrativa, sobre os processos de ensino e aprendizagem (FREITAS; FIORENTINI, 2008). Estas narrativas são relevantes à constituição docente, pois, como indicam Nacarato e Passeggi (2011, p. 1), apoiados em Larrosa (2002), "ao escrever sobre si, sobre suas experiências, sobre suas trajetórias pessoais, estudantis ou profissionais, o professor 
reflete, se autointerpreta e toma consciência de si mesmo como um sujeito histórico, cultural, social e pessoal; o sujeito da intersubjetividade".

Neste contexto, a narrativa passa a ser um instrumento da formação dos professores, pois "ao mesmo tempo que o sujeito organiza suas ideias para o relato - quer escrito, quer oral - ele reconstrói sua experiência de forma reflexiva e, portanto, acaba fazendo uma autoanálise que lhe cria novas bases de compreensão de sua própria prática" (CUNHA, 1997, p. 187). A autora também destaca que há uma relação dialética entre narrativa e experiência, provocando mútuas influências.

A narrativa da minha constituição profissional tem início no curso de Licenciatura em Matemática, a partir de um currículo composto por disciplinas de formação específica e didático-pedagógicas. A escolha deste curso ocorreu ainda na infância, talvez não de modo consciente, quando gostava de ensinar a tabuada de multiplicação às bonecas, perfazendo a formação básica, quando auxiliava os demais colegas com dúvidas relativas à Matemática.

No decorrer do curso de Licenciatura em Matemática, percebia que "dominar" os conceitos matemáticos não bastava para o exercício da docência. Era preciso, para ensinar, "conhecer seus fundamentos epistemológicos, sua evolução histórica, a relação da Matemática com a realidade, seus usos sociais e as diferentes linguagens com as quais se pode representar ou expressar um conceito matemático" (FIORENTINI, 2012, p. 110). Logo, a formação docente distinguia-se de outros cursos, pois representava "uma etapa para a formalização do conhecimento profissional ligado ao ato de ensinar" (LOPES; D'AMBROSIO, 2015, p. 23).

Entre disciplinas específicas e didático-pedagógicas, além dos conceitos matemáticos, experenciei, nos estágios supervisionados, os primeiros ensaios como professora de Mate- mática, que foram relevantes para a construção de saberes relacionados à atuação docente (FIORENTINI; CASTRO, 2003) e na construção da identidade profissional (PIMENTA; LIMA, 2004; PIMENTA, 1997). Nos estágios, conforme destacam Almeida e Pimenta (2014, p. 73):

[...] começam a ser construídos os saberes, as
habilidades, posturas e atitudes que formam o
profissional. Em períodos de estágio, esses co-
nhecimentos são ressignificados pelo aluno es-
tagiário a partir de suas experiências pessoais
em contato direto com o campo de trabalho
que, ao longo da vida profissional, vão sendo
reconstruídos no exercício da profissão.

Uma destas experiências de estágio foi, inclusive, a temática elegida para o meu TrabaIho de Conclusão de Curso - TCC. Neste, discuti os processos de compreensão pelo professor em formação inicial, ao ensinar função de 10 grau, considerando o uso de um software, o que envolvia a compreensão do conceito, o conhecimento didático, a compreensão dos alunos e de como estes aprendiam este conteúdo (SCHREIBER; BATTISTI, 2017). Foram as primeiras leituras relativas aos saberes docentes, discutindo com importantes autores, como Shulman (1986), Tardif (2014) e Gauthier et al (2013), sendo estes também considerados em minha pesquisa de doutorado.

Com a conclusão da formação inicial, segui para o mestrado e, posteriormente, o doutorado. 0 primeiro com ênfase na Estatística Aplicada, em um universo distinto do curso de Licenciatura em Matemática, realçava a aplicação de modelos estatísticos, no meu caso, a modelagem de doenças infecciosas, como a Síndrome da Imunodeficiência Humana Adquirida - SIDA/AIDS, malária, tuberculose e tétano (SCHREIBER, 2015). No segundo, doutorado em Educação em Ciências, a ênfase está na Educação Estatística, onde passei a discutir a formação e a prática docente, a partir da minha própria atuação em sala de aula e das vivências 
relacionadas ao curso de Licenciatura em $\mathrm{Ma}$ temática, em um movimento dinâmico entre o fazer e o pensar sobre o fazer (FREIRE, 2016).

Esta mudança, entre a Estatística Aplicada e uma pesquisa sobre a formação de professores em Estatística, já demonstrava uma antiga inquietação: a prática docente. Tal anseio foi então superado no final do mestrado, a partir da primeira experiência docente com estudantes do 6 o ano do Ensino Fundamental (antiga 5 a série), em uma instituição privada. Foi um período de muitas aprendizagens, em um processo de constituição e mobilização de saberes docentes (SHULMAN, 1986), construídos nas relações com estudantes e professores. Neste sentido, Ponte et al (2001, p. 1-2) destacam que:

Os primeiros anos da profissão docente são cruciais para o desenvolvimento do conhecimento e identidade do professor. Trata-se de um período em que o jovem professor se encontra entregue a si próprio, tendo de construir formas de lidar com toda uma variedade de papéis profissionais, em condições variadas e, muitas vezes, bastante adversas. 0 confronto diário com situações complexas que exigem uma resposta imediata, faz deste período uma fase de novas aprendizagens e de reequacionamento das suas concepções sobre a escola, a educação, o currículo, a disciplina que ensina, os alunos e o próprio trabalho em si.

Como indicado por Ponte et al (2001), os primeiros anos de docência são constituídos por novas aprendizagens e por um reequacionamento docente. Estes também foram contrastados aos saberes adquiridos na formação inicial, na Licenciatura em Matemática, e com a própria história escolar, lembrando, por exemplo, dos professores que fizeram parte do meu desenvolvimento acadêmico na Educação Básica e no Ensino Superior. Neste sentido, Tardif $(2014$, p. 53) ressalta que a prática é “um processo de aprendizagem através do qual os professores retraduzem sua formação e a adaptam à profissão", provocando, assim, "um efeito de retomada crítica (retroalimentação) dos saberes adquiridos antes ou fora da prática profissional".

Com o encerramento do primeiro ano letivo e o reinício do segundo, uma nova oportunidade de experiência docente se aproximava: lecionar a disciplina de Matemática para estudantes do Ensino Médio, em uma instituição pública federal. Foi um momento importante para conviver com discentes em uma diferente faixa etária, além de novos conceitos matemáticos, uma maior quantidade de turmas e outras formas de avaliação.

Além da docência, no decorrer deste ano letivo, um importante momento da pesquisa de doutorado também foi se constituindo - o grupo colaborativo entre professores de Matemática, com ênfase em Educação Estatística, o Grupo MoSaiCo Edu. ${ }^{2}$ Este foi idealizado a partir de discussões no Grupo de Pesquisa em Educação Estatística - EduEst, do qual faço parte, e com a participação em eventos científicos. Além disso, minhas primeiras experiências docentes já demonstravam a relevância de um espaço para compartilhar e problematizar a prática, ou seja, onde se pudesse partilhar as dúvidas e anseios que cercavam o exercício da docência. Neste caso, nos contextos colaborativos, conforme destaca Fiorentini (2010, p. 582):

formadores, professores e futuros professores analisam e discutem os problemas e desafios trazidos pelos professores, episódios de aula narrados e documentados pelos professores, e negociam conjuntamente significados e outras possibilidades de intervenção em suas práticas escolares, sobretudo tarefas e atividades exploratório-investigativas.

A heterogeneidade dos participantes do grupo colaborativo, com professores formadores, professores da Educação Básica e Licencia-

2 Para maiores informações sobre o Grupo MoSaiCo Edu, acesse: https://mosaico.furg.br/. 
dos em Matemática, recentemente formados, propiciaram (e estão propiciando) importantes discussões acerca das práticas docentes. Cada encontro vem sendo constituído por leituras teóricas, entrelaçadas com as narrativas das próprias experiências docentes, sendo que a “fundamentação teórica e metodológica de tais práticas possibilitam a produção de teoria sobre a prática pedagógica e a formação de professores" (GRANDO; NACARATO, 2013, p. 13).

Neste processo, as características de um contexto colaborativo, como: i) voluntariedade, identidade e espontaneidade; ii) liderança compartilhada ou corresponsabilidade; iii) apoio e respeito mútuo, vêm sendo desenvolvidas no decorrer dos encontros, realizados mensalmente, desde agosto de 2018. Tem-se a consciência de que se tornar colaborativo não é algo imediato e que requer um trabalho em conjunto, com respeito mútuo e objetivos comuns, a serem alcançados. Logo, “à medida que seus integrantes vão se conhecendo e adquirem e produzem conjuntamente conhecimentos, os participantes adquirem autonomia e passam autorregular-se e a fazer valer seus próprios interesses, tornando-se, assim, grupos efetivamente colaborativos" (FIORENTINI, 2004, p. 53).

Os encontros do grupo colaborativo são audiogravados e analisados, e já vêm indicando a riqueza do contexto colaborativo, por meio das narrativas, para as discussões relativas à prática educativa, juntamente com importantes referenciais teóricos desta área. Estes permitem aos professores um "encontro de movimento do pensamento, da reflexão, do questionamento, da ressignificação de experiências, reelaboração de outras práticas e compreensão da própria prática docente" (PRADO; DAMASCENO, 2007, p. 23).

As narrativas dos professores que fazem parte do grupo colaborativo, assim como as minhas histórias, aqui narradas, são impor- tantes para o desenvolvimento profissional e acadêmico. Ao escrever sobre as experiências, passamos a refletir pedagogicamente acerca das consequências da atuação como docente (PASSOS; OLIVEIRA; GAMA, 2013). Além disso, "através deste diálogo narrativo entre reflexão e interpretação, a experiência se transforma em saber pedagógico sobre os conteúdos" (MCEWAN; EGAN, ${ }^{3} 2005$, p. 60, tradução nossa).

\section{Algumas considerações}

As experiências narradas, singulares e inseparáveis (LARROSA, 2002), apresentaram os espaços formativos de duas professoras, indicando o encontro destas docentes com as temáticas estudadas na pós-graduação, mais especificamente, com a Educação Estatística. Como seres inacabados (FREIRE, 2016), seu processo de formação foi (e está sendo) construído a partir das mudanças que ocorrem ao longo da carreira profissional e de vida, ou seja, estão relacionadas às diferentes abordagens pedagógicas, às reformas escolares, ao desenvolvimento social e político, além dos acontecimentos que ocorrem na vida pessoal (PASSOS; OLIVEIRA; GAMA, 2013).

A partir das narrativas compartilhadas, pode-se refletir sobre os sentimentos, as memórias e as experiências das docentes que as levaram ao campo da educação; a começar pelas experiências na infância e passando pela formação profissional, ressaltando a importância destes espaços para a constituição das autoras Thays e Karla, como professoras e pesquisadoras. Isso ocorre, pois "narrar histórias e contar a vida caracteriza-se como uma das possibilidades de tecer identidade, de compreender como nos tornamos professores e das configurações que nos são forjadas nos

3 "A través de este diálogo narrativo entre reflexión e interpretación, la experiencia se transforma en saber pedagógico sobre los contenidos". (MCEWAN; EGAN, 2005, p. 60) 
nossos percursos de vida-formação" (SOUSA; ALMEIDA, 2012, p. 46).

A constituição do fazer docente de Thays sofre a influência das experiências vivenciadas e sentidas em sua interação com suas professoras, desde a infância, até à graduação em Psicologia. Tal influência é envolta de emoções, afetividade e lembranças. Diferente da trajetória de Karla, Thays tem sua formação inicial em Pedagogia, por isso, durante a graduação, foi conquistada pelo campo da Matemática e, mais especificamente, da Educação Estatística, a partir do convívio e de vivências em um grupo de extensão. Experiência esta que the possibilitou adentrar no âmbito da pesquisa científica, ingressando no mestrado e doutorado com a curiosidade e a motivação de estudar os processos de ensinar e aprender Estatística, de forma lúdica, nos Anos Iniciais do Ensino Fundamental.

$\mathrm{Na}$ trajetória da Professora Karla, entre a escolha pela Licenciatura em Matemática, o mestrado em Estatística Aplicada e o doutorado com ênfase na formação Estatística do professor de Matemática, muitas experiências formaram e transformaram o seu fazer profissional. Estas também envolveram a docência, em dois diferentes contextos - com estudantes do 60 ano do Ensino Fundamental e do Ensino Médio, além da constituição e participação em um grupo colaborativo de professores de Matemática.

Em suma, percebeu-se que o sujeito professor se constitui não somente a partir da conclusão de um curso de graduação, mas, sim, ao longo de toda a sua história de vida, das suas experiências com os outros, desde a infância, com seus professores e colegas, na interação com seus pares, envolvendo aspectos afetivos que vão direcionando os sujeitos para esta ou aquela área, que, nesse caso, culminou na pesquisa científica no campo da Educação Estatística. Além de experiências profissionais que, ao longo do tempo, vão legitimando a profissão de educador na história das professoras.

\section{Referências}

ALMEIDA, M. I.; PIMENTA, S. G. Estágios supervisionados na formação docente. São Paulo: Cortez, 2014. BATANERO, C. Didáctica de la Estadística. Granada: GEEUG, Departamento de Didáctica de la Matemática, Universidad de Granada, Espanha, 2001. Disponível em: <http://www.pucrs.br/ciencias/viali/graduacao/matematica/material/referencias/didacticaestadistica.pdf>. Acesso em: 07 jan. 2019.

BRASIL. Parâmetros Curriculares Nacionais: Matemática. Primeiro e segundo ciclo do Ensino Fundamental. Brasília, DF: Ministério da Educação; Secretaria de Educação Fundamental, 1997. 142p. Disponivel em: <http://portal.mec.gov.br/seb/arquivos/ pdf/livro03.pdf>. Acesso em: 10 dez. 2018.

BRASIL. Parâmetros Curriculares Nacionais: Matemática. Terceiro e quarto ciclo do Ensino Fundamental. Brasília, DF: Ministério da Educação; Secretaria de Educação Fundamental, 1998. 148p. Disponivel em: <http://portal.mec.gov.br/seb/arquivos/ pdf/matematica.pdf>. Acesso em: 10 dez. 2018.

BRASIL. Parâmetros Curriculares Nacionais: Ciências da Natureza, Matemática e suas Tecnologias. Ensino Médio. Brasília, DF: Ministério da Educação; Secretaria de Educação Média e Tecnológica, 2000. 58p. Disponivel em: <http://portal.mec.gov.br/seb/ arquivos/pdf/ciencian.pdf>. Acesso em: $10 \mathrm{dez}$. 2018.

BRASIL. Orientações curriculares para o Ensino Médio: Ciências da natureza, matemática e suas tecnologias. Brasília, DF: Ministério da Educação; Secretaria de Educação Básica, 2006. 135p. Disponivel em: <http://portal.mec.gov.br/seb/arquivos/pdf/ book_volume_02_internet.pdf>. Acesso em: $10 \mathrm{dez}$. 2018.

BRASIL. Diretrizes Curriculares Nacionais Gerais da Educação Básica. Brasília, DF: Ministério da Educação; Secretaria de Educação Básica; Diretoria de Currículos e Educação Integral, 2013. Disponivel em: <http://portal.mec.gov.br/docman/julho-2013-pd- 
f/13677-diretrizes-educacao-basica-2013-pdf/file>. Acesso em: 10 dez. 2018.

BRASIL. Base Nacional Comum Curricular. Brasília, DF: Ministério da Educação, 2018. Disponivel em: <http:// basenacionalcomum.mec.gov.br/wp-content/uploads/2018/12/BNCC_19dez2018_site.pdf>. Acesso em: 10 dez. 2018.

BRUNER, J. A Construção narrativa da realidade. Tradução de Waldemar Ferreira Netto. Critical Inquiry, v. 18, n. 1, p. 1-21, 1991. Disponivel em: <https:/ / www. academia.edu/4598706/BRUNER_Jerome._A_constru\%C3\%A7\%C3\%A30_narrativa_da_realidade>. Acesso em: 20 dez. 2018.

BRUNER, J. Realidade mental, mundos possiveis. Tradução de Marcos A. G Domingues. Porto Alegre: Artes Médicas, 1997.

CAZORLA, I. M.; KATAOKA, V. Y.; SILVA, C. B. Trajetória e perspectivas da educação estatística no Brasil: um olhar a partir do GT12. In: LOPES, C. E.; COUTINHO, C. Q. S.; ALMOULOUD, S. A. (Orgs.). Estudos e reflexões em Educação Estatística. Campinas, SP: Mercado de Letras, 2010. p. 19-44.

CAZORLA, I. M. MAGINA, S; GITIRAN, V; GUIMARÃES, G. Estatística para os anos iniciais do Ensino Fundamental. [livro eletrônico]. Brasília, DF: SBEM, 2017. Disponivel em: <http://www.sbem.com.br/files/ ebook_sbem.pdf>. Acesso em: 22 mar. 2018.

CLANDININ, D. J.; CONNELLY, F. M. Pesquisa narrativa: experiência e história em pesquisa qualitativa. 2. ed. Tradução do Grupo de Pesquisa Narrativa e Educação de Professores ILEEI/UFU. Uberlândia, MG: EDUFU, 2015.

CUNHA, M. I. CONTA-ME AGORA!: as narrativas como alternativas pedagógicas na pesquisa e no ensino. Revista da Faculdade de Educação, [S. I.], v. 23, n. 1-2, p. 185-195, jan. 1997. Disponível em: <http://www.scielo.br/scielo.php?pi$d=$ S0102-25551997000100010\&script=sci_arttext $>$. Acesso em: 05 jan. 2019.

DEMO, P. Pesquisa e construção de conhecimento: metodologia científica no caminho de Habermas. Rio de Janeiro: Tempo Brasileiro, 1997.
DEMO, P. Educar pela pesquisa. Campinas, SP: Autores Associados, 2015.

FIORENTINI, D. Pesquisar práticas colaborativas ou pesquisar colaborativamente? In: BORBA, M. C.; ARAÚJO, J. L. (Orgs.). Pesquisa qualitativa em Educação Matemática. Belo Horizonte: Autêntica, 2004. p. 47-76.

FIORENTINI, D. Desenvolvimento profissional e comunidades investigativas. In: DALBEN, A. et al. (Orgs.). Convergências e tensões no campo da formação e do trabalho docente: Educação ambiental - Educação em ciências - Educação em espaços não escolares - Educação matemática. Belo Horizonte: Autêntica, 2010. p. 570-590.

FIORENTINI, D. A formação matemática e didático-pedagógica nas disciplinas da licenciatura em matemática. Revista de Educação PUC, Campinas, SP, n. 18, p. 107-115, 2012. Disponivel em: <https:// seer.sis.puc-campinas.edu.br/seer/index.php/reveducacao/article/view/266>. Acesso em:11 jan. 2019.

FIORENTINI, D., CASTRO, F. C. Tornando-se Professor de Matemática: o caso de Allan em prática de ensino e estágio supervisionado. In: FIORENTINI, D. (Org.). Formação de professores de Matemática: explorando novos caminhos com outros olhares. Campinas, SP: Mercado de Letras, 2003.

FREIRE, P. Pedagogia da autonomia. 53. ed. Rio de Janeiro: Paz e Terra, 2016.

FREITAS, M.; FIORENTINI, D. Desafios e potencialidades da escrita na formação docente em matemática. Revista Brasileira de Educação, v. 13, n. 37, p. 138189, 2008. Disponivel em: <http://www.scielo.br/ pdf/rbedu/v13n37/12.pdf>. Acesso em: 15 jan. 2019.

GAL, I. Adults' Statistical Literacy: meanings, components, responsibilities. International Statistical Review, v. 70, n. 1, p. 1-25, 2002. Disponivel em: <https://iase-web.org/documents/intstatreview/02. Gal.pdf>. Acesso em: 30 nov. 2018.

GAL, I. Prefácio. In: SAMÁ, S.; PORCIÚNCULA, M. (Orgs.). Educação Estatística: ações e estratégias pedagógicas no ensino básico e superior. Curitiba: CRV, 2015. p. 13-14. 
GAUTHIER, C.; MARTINEAU, S.; DESBIENS, J.; MALO, A.; SIMARD, D. Por uma teoria da pedagogia: pesquisas contemporâneas sobre o saber docente. Ijuí: Editora Unijuí, 2013.

GRANDO, R. C.; NACARATO, A. M. As potencialidades do trabalho colaborativo para o ensino e a aprendizagem em estocástica. In: NACARATO, A. M.; GRANDO, R. C. (Orgs.). Estatística e probabilidade na Educação Básica: professores narrando suas experiências. Campinas, SP: Mercado de Letras, 2013. p. 11-32.

KISHIMOTO, T. M. 0 jogo e a Educação Infantil. São Paulo: Pioneira, 1998.

KISHIMOTO, T. M. Brinquedos e brincadeiras na educação infantil. In: SEMINÁRIO NACIONAL: CURRÍCULO EM MOVIMENTO, 1., 2010, Belo Horizonte. Anais... Belo Horizonte: UFMG, 2010. p. 1-20. Disponível em: <http://portal.mec.gov.br/docman/dezembro-2010-pdf/7155-2-3-brinquedos-brincadeirastizuko-morchida/file>. Acesso em: 13 jun. 2017.

LARROSA, J. B. Notas sobre a experiência e o saber de experiência. Revista Brasileira de Educação, n. 19, p. 20-28, jan./fev./mar/abr. 2002. Disponivel em: <http:// www.scielo.br/pdf/rbedu/n19/n19a02.pdf>. Acesso em: 19 dez. 2018.

LOPES, C. E. Os desafios para educação estatística no currículo de matemática. In: LOPES, C. E.; COUTINHO, C. Q. S.; ALMOULOUD, S. A. (Orgs.). Estudos e reflexões em Educação Estatística. Campinas, SP: Mercado de Letras, 2010. p. 47-64.

LOPES, C. E.; D’AMBROSIO, B. S. Perspectivas para a Educação Estatística de futuros educadores matemáticos de infância. In: SAMÁ, S.; PORCIÚNCULA, M. (Orgs.). Educação Estatística: ações e estratégias pedagógicas no ensino básico e superior. Curitiba: CRV, 2015. p. 17-27.

LUCKESI, C. C. Desenvolvimento dos estados de consciência e ludicidade. Cadernos de Pesquisa do Núcleo de FACED/UFBA, v. 2, n. 21, p. 9-25, 1998.

LUCKESI, C. C. Brincar III: a criança e sua poética. (Material obtido através do website de Cipriano Carlos Luckesi), 2005. 4p.

MCEWAN, H.; EGAN, K. La narrativa en la enseñan- za, el aprendizaje y la investigación. 1â ed. 1. reimp. Buenos Aires: Amorrortu, 2005.

NACARATO, A. M.; PASSEGGI, M. C. F. B. S. Narrativas da experiência docente em matemática de professoras alunas em um curso de pedagogia. In: SIMPÓSIO INTERNACIONAL DE GÊNEROS TEXTUAIS, 6., 2011, Natal. Anais... Natal: UFRN, 2011. p. 1-14.

PASSOS, C.; OLIVEIRA, R.; GAMA, R. Narrativas em grupo de professores e licenciandos: resignificando a aprendizagem da matemática. Revista de Educação PUC, Campinas, SP, v. 18, n. 3, p. 327-339, 2013. Disponível em: <http://periodicos.puc-campinas.edu.br/ seer/index.php/reveducacao/article/view/2368>. Acesso em: 23 dez. 2018.

PIMENTA, S. G. Formação de professores - Saberes da docência e identidade do professor. Nuances, v. 3, 1997. Disponível em: <https://edisciplinas.usp. br/pluginfile.php/1287224/mod_resource/content/1/Pimenta_Form\%20de\%20profs\%20e\%20saberes\%20da\%20docencia.pdf>. Acesso em: $12 \mathrm{dez}$. 2018.

PIMENTA, S. G., LIMA, M. S. Estágio e docência. São Paulo: Cortez, 2004.

PONTE, J. P.; GALVÃO, C.; SANTOS, F. T.; OLIVEIRA, H. O início da carreira profissional de jovens professores de Matemática e Ciências. Revista de Educação, Lisboa: Departamento de Educação da Faculdade de Ciências da Universidade de Lisboa. v. 10, n. 1, p. 3145, 2001. Disponível em: <http://repositorio.ul.pt/ bitstream/10451/4286/1/01-Ponte-G-S-O-(Indu\%C3\%A7\%C3\%A3o-RE).pdf>. Acesso em: 10 jan. 2019.

PORCIÚNCULA, M.; SAMÁ, S. Projetos de aprendizagem: uma proposta pedagógica para a sala de aula estatística. In: SAMÁ, S.; PORCIÚNCULA, M. (Orgs.). Educação Estatística: ações e estratégias pedagógicas no ensino básico e superior. Curitiba: CRV, 2015. v. 1, p. 133-141.

PRADO, G. V. T.; DAMASCENO, E. A. Saberes docentes: narrativas em destaque. In: VARANI, A.; FERREIRA, C. R.; PRADO, G. V. T. (Orgs.). Narrativas docentes: trajetórias de trabalhos pedagógicos. Campinas, SP: Mercado de Letras, 2007. p. 15-27.

SCHREIBER, K. P. Modelagem do número reprodu- 
tivo básico transformado de doenças infecciosas via a função de distribuição Gama Condicional Modificada. 2015. 149 f. Dissertação (Mestrado em Biometria e Estatística Aplicada) - Programa de Pós-Graduação em Biometria e Estatística Aplicada, Universidade Federal Rural de Pernambuco, Recife. 2015. Disponivel em: <http://www.ppgbea.ufrpe.br/ sites/www.ppgbea.ufrpe.br/files/documentos/dissertacao_karla_priscilla_schreiber.pdf>. Acesso em: 01 dez. 2018.

SCHREIBER, K. P.; BATTISTI, I. K. Processos de compreensão pelo professor em formação inicial ao ensinar função de 1o grau considerando o uso de um software. Alexandria: Revista de Educação em Ciência e Tecnologia, v. 10, n. 2, p. 127-145, nov. 2017. Disponivel em: <https://periodicos.ufsc.br/ index.php/alexandria/article/viewFile/1982-5153. 2017v10n2p127/35388>. Acesso em: 15 dez. 2018.

SHULMAN, L. Those who understand: knowledge growth in teaching. Educational researcher, v. 15, n. 2, p. 4-14, 1986. Disponivel em: <http://www.fisica.uniud.it/URDF/masterDidSciUD/materiali/pdf/ Shulman_1986.pdf>. Acesso em:10 dez. 2018.

SILVA, A. J. N. Formação lúdica do futuro professor de matemática por meio do laboratório de ensino. 2014. 196 f. Dissertação (Mestrado em Educação) -
Faculdade de Educação, Universidade de Brasília, Brasília, 2014. Disponivel em: <http://repositorio. unb.br/bitstream/10482/16611/1/2014_AmericoJuniorNunesdaSilva.pdf>. Acesso em: 10 fev. 2017.

SOUSA, E, C; ALMEIDA, J, B. Narrar histórias e contar a vida: memórias cotidianas e histórias de vida de educadores baianos. In: ABRAHÃO, M. H. M. B. (Org.). Pesquisa (auto) biográfica em rede. Natal: UFRN; Porto alegre: IPUCRS; Salvador: EDUNEB, 2012. p. 29-31.

TARDIF, M. Saberes docentes e formação profissional. 17. ed. Petrópolis, RJ: Vozes, 2014.

VOTTO, T. R. As potencialidades lúdicas nas estratégias para o ensino e a aprendizagem estatística nos anos iniciais do ensino fundamental. 2018. 175 f. Dissertação (Mestrado em Educação em Ciências: Química da Vida e Saúde) - Programa de Pós-Graduação em Educação em Ciências: Química da Vida e Saúde, Universidade Federal Do Rio Grande, Rio Grande, 2018. Disponivel em: <https://sistemas. furg.br/sistemas/sab/arquivos/bdtd/0000012406. pdf>. Acesso em: 20 out. 2018.

Recebido em: 30.01.2019

Aprovado em: 02.04.2019

Thays Rodrigues Votto é Mestre em Educação em Ciências pela Universidade Federal do Rio Grande (FURG). Doutoranda, bolsista CAPES, no Programa de Pós-Graduação em Educação em Ciências: Química da Vida e Saúde pela Universidade Federal do Rio Grande (FURG). Grupo de Pesquisa em Educação Estatística - EduEst. e-mail: thayvotto@hotmail.com.

Universidade Federal do Rio Grande (FURG), Instituto de Matemática Estatística e Física (IMEF). Av. Itália Km 8. (53) 98462-9266.

Karla Priscila Schreiber é Mestre em Biometria e Estatística Aplicada pela Universidade Federal Rural de Pernambuco (UFRPE). Doutoranda, bolsista CAPES, no Programa de Pós-Graduação em Educação em Ciências: Química da Vida e Saúde pela Universidade Federal do Rio Grande (FURG). Grupo de Pesquisa em Educação Estatística - EduEst. e-mail: karla.pschreiber@hotmail.com

Universidade Federal do Rio Grande (FURG), Instituto de Matemática Estatística e Física (IMEF). Av. Itália Km 8. (53) 99105-9937.

Mauren Porciúncula é Doutora em Informática na Educação pela Universidade Federal do Rio Grande do Sul (UFRGS). Professora adjunta na Universidade Federal do Rio Grande (FURG). Grupo de Pesquisa em Educação Estatística - EduEst. e-mail: mauren@furg.br

Universidade Federal do Rio Grande (FURG), Instituto de Matemática Estatística e Física (IMEF). Av. Itália Km 8. (53) 99999-9985. 